\title{
PHYSICAL AND MECHANICAL PROPERTIES OF TRANSITION ZONE OF BIMETAL PRODUCED BY AUTONOMOUS VACUUM BRAZING OF COPPER ON STEEL
}

\author{
M.G. ATROSHENKO, M.A. POLESHCHUK, A.V. SHEVTSOV, A.L. PUZRIN, \\ D.D. MISHCHENKO, I.P. SEREBRYANIK and A.I. BORODIN \\ E.O. Paton Electric Welding Institute, NASU \\ 11 Bozhenko Str., 03680, Kiev, Ukraine. E-mail: office@paton.kiev.ua
}

\begin{abstract}
The physical and mechanical properties of the joining zone of metal produced by autonomous vacuum brazing of copper M1 on steel billets were determined. During tensile test the fracture of standard specimens occurred always in the copper part. At the same time, the strength properties of brazed copper layer in the initial state exceeded the reference values for wrought and annealed copper M1. The ultimate tear strength of brazed copper layer determined on the special specimens is equal to the temporary rupture strength of steel 20. The investigations of physical characteristics of the joining zone showed that during technical calculations the additional electrical and thermal resistances of the contact zone can be neglected. 13 Ref., 1 Table, 7 Figures.
\end{abstract}

$\boldsymbol{K} \boldsymbol{e} \boldsymbol{y} \boldsymbol{w} \boldsymbol{O} \boldsymbol{d} \boldsymbol{s}:$ autonomous vacuum brazing steel-copper bimetal, mechanical properties of joining zone, electrical and thermal resistance of contact

During the production of separate units of machines and devices, in some cases the bimetal copper-steel billets are used manufactured beforehand. The use of such billets allows producing parts operating reliably under high electrical, thermal and mechanical loads. During their operation the physical and mechanical properties of metal in the zone of copper with steel joining are essentially important. The transition steelcopper zone should have a minimum electrical and thermal resistance and a sufficiently high mechanical strength.

It is obvious that the specific values of these variables depend on the method of manufacture of copper-steel billet.

The bimetallic strips of up to $4 \mathrm{~mm}$ thickness used for production of electric engineering power equipment are manufactured mainly by joint rolling of steel and copper strips or multilayer packets [1, 2]. The billets of other shapes with a large cross-section can be produced by diffusion welding in vacuum [3], explosion welding [4], friction stir welding [5], and also high-temperature brazing [6]. For manufacture of large-size billets such as water-cooled hearth electrodes of arc steelmelting furnaces of direct current, sliding bearings of large diameters, etc., different methods of fusion welding are applied [7], including elec- tro-slag welding [8], pouring of molten copper on steel heated to $900{ }^{\circ} \mathrm{C}$ is used [9].

Recently, the method was developed to produce large-size copper-steel billets by melting copper in autonomous vacuum. The method is based on using autovacuum effect, which consists in spontaneous cleaning the surfaces of steel billets from oxide films at their heating to the temperature above $1000{ }^{\circ} \mathrm{C}$ under the conditions of a closed volume. In this case, oxygen in the composition of oxide film diffuses deep into the steel billet. At the same time, the oxidation of its surface by oxygen from the closed volume occurs. The diffusion process continues as long, unless all the oxygen of the closed volume is consumed and oxide film disappears. The time of oxide film removal from the surface of steel billet can be reduced by preliminary pumping out of air from the closed volume [10].

For manufacture of bimetal product, a closed volume is created on the billet steel part, the future interface of bimetal. The copper is placed into it in the amount necessary to produce the copper part of the billet. After sealing the volume with copper the assembly is heated to 1130 $1150{ }^{\circ} \mathrm{C}$. At this temperature the cleaning of steel surface from oxide film occurs resulting in formation of a strong metallic bonding with steel after copper melting [11].

The aim of this work is the determination of physical and mechanical characteristics of the 


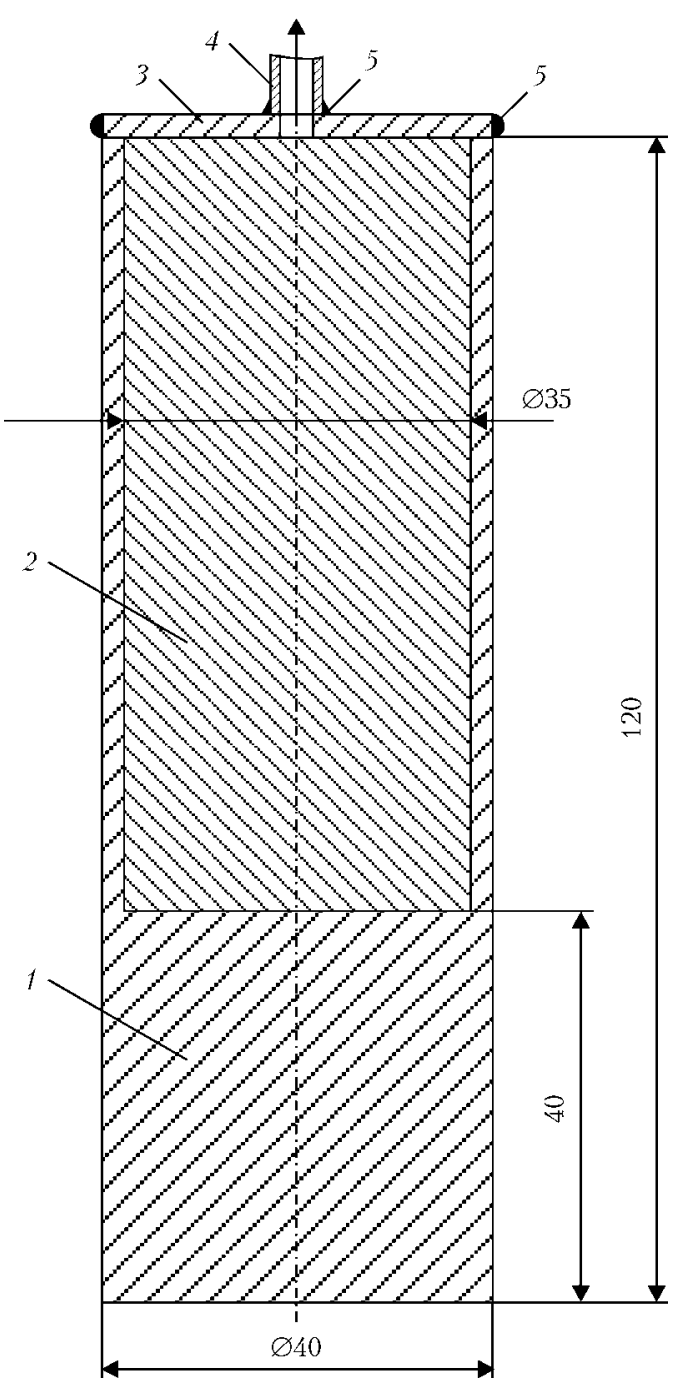

Figure 1. Sketch of pilot billet for brazing: 1 - hollow cylinder; 2 - melting component (copper); 3 - cover; 4 - branch pipe for vacuuming; 5 - sealing welds

steel-copper transition zone, produced by melting copper in autonomous vacuum, namely, of electrical and thermal resistance, mechanical strength, tensile and tear strength.

To carry out investigations the hollow cylinders with a massive bottom of steel 20 were manufactured. The cavities of cylinders were tightly filled with cuttings of copper sheet M1 of $2.5 \mathrm{~mm}$ thickness. The opening of the cavity was closed by steel cover, to the center of which a thinwalled steel pipe was welded-in. The cover was sealed by argon arc welding (Figure 1).

The cylinders prepared for testing were placed in the thermal furnace with a usual atmosphere. The branch pipe-vacuum conductor was brought out to the outside and connected to the forevacuum pump through the gate valve with a manovacuum gauge (Figure 2 ).

Before heating, the evacuation was created inside the cylinders by the forevacuum pump and the gate valve was closed. The thermal furnace was heated to $1150{ }^{\circ} \mathrm{C}$ and after $30 \mathrm{~min}$ of iso-

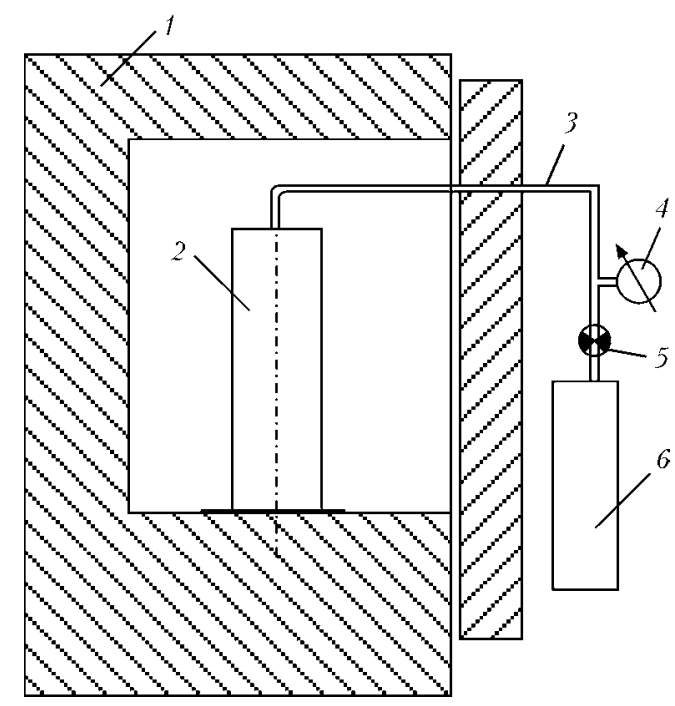

Figure 2. Scheme of carrying out autonomous vacuum brazing: 1 - thermal furnace; 2 - pilot billet; 3 - vacuum conductor; 4 - manovacuum gauge; 5 - gate valve; $6-$ forevacuum pump

thermal holding it was switched off and the door was opened. The cylinders were left inside the furnace until their complete cooling. During heating the evacuation inside the cylinders according to the indications of the manovacuum gauge was almost unchanged.

After cooling each cylinder was cut along the forming part into the four equal parts, of which the specimens for mechanical tests were manufactured, the measurements of electrical resistance and study of microstructure of the transition zone were carried out.

Figure 3 shows a photo of macrosection of the longitudinal template of cylindrical copper-steel billet. The visual inspection of macrosection using magnifying glass of 10 -fold increase did not reveal defects, violating the integrity of metal in the brazed copper and in the zone of its joining with steel.

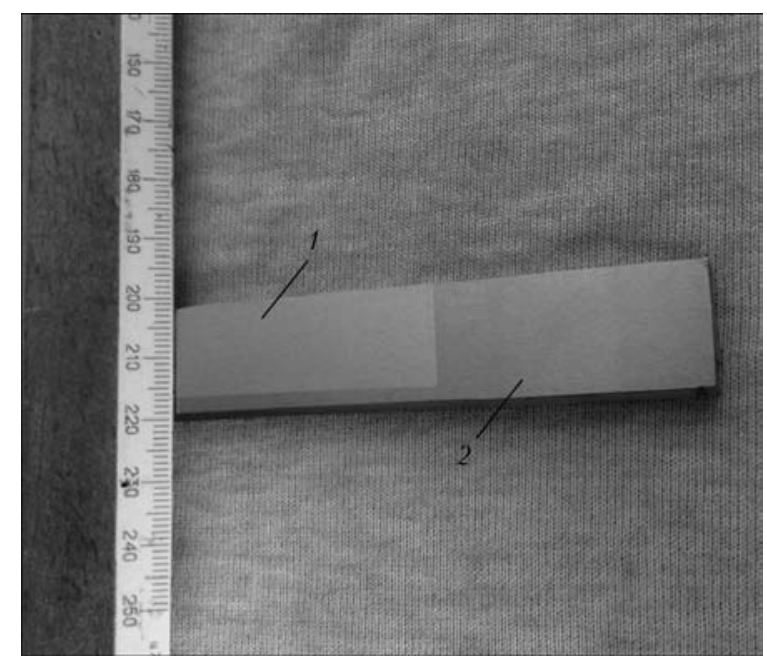

Figure 3. Macrosection of steel-copper bimetal joint: 1 copper; 2 - steel 


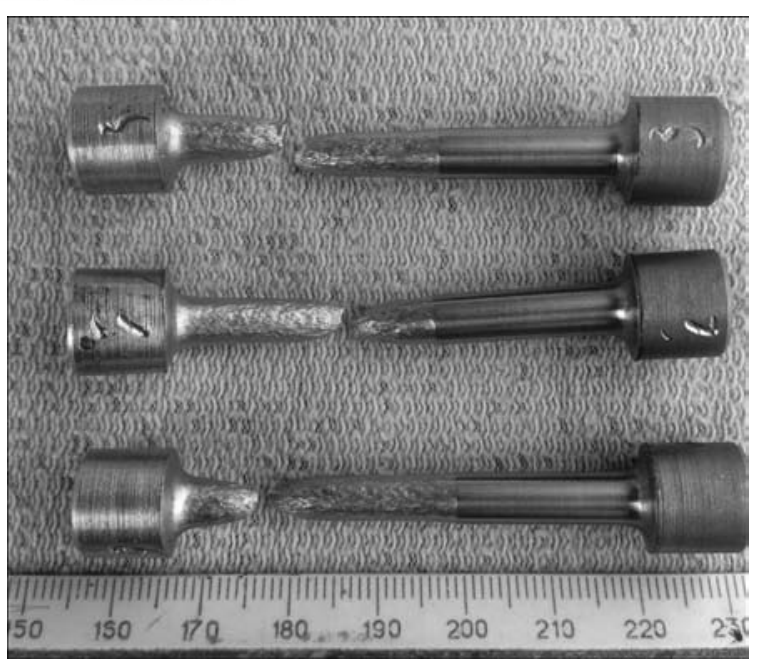

Figure 4. Specimens after tensile tests

To carry out mechanical tensile tests the specimens with $6 \mathrm{~mm}$ diameter of rupture part and $40 \mathrm{~mm}$ length were manufactured. The steel-copper contact was located in the middle of the rupture part. During tests the fracture of all the specimens occurred along the copper part $\left(\mathrm{Fi}_{-}\right.$ gure 4). This means that the strength of the copper-steel contact is higher than the tensile strength of copper.

The test results are given in the Table.

The given data evidence that the values of mechanical properties of the tested specimens are higher than those of the deformed and annealed copper according to the reference values [12].

The main characteristic of quality of bimetal joint is the tear strength of the brazed layer. To obtain the reliable data on tear strength the specimens of a special type should be tested, which have a ring-type groove on a stronger joint element (Figure 5).

Such a groove reduces the area of contact of copper with steel, at the same time preserving constant diameter of the copper part of the specimen [13]. The tests showed that the fracture occurred along the line of joining. The average value of ultimate tear strength was $480 \mathrm{MPa}$, that corresponds to the value of ultimate rupture strength of annealed steel 20 [12].

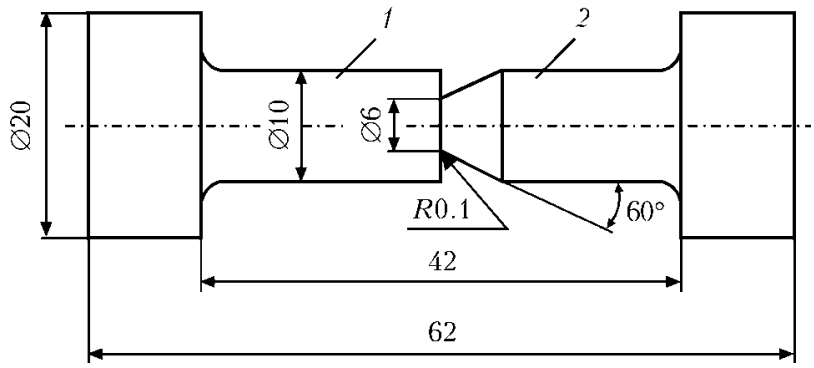

Figure 5. Sketch of specimen for testing on static tear: 1 copper; 2 - steel part
Thus, the results of above-mentioned mechanical tests evidence that the method of autonomous vacuum brazing allows producing the coppersteel bimetal with high strength of layer joining.

The other important characteristics, which provide a reliable operation of bimetal at high electrical and thermal loads, are the values of electric and thermal resistance in the steel-copper contact. The lower are these resistances, the better is heat removal through the interface and lower the electrical losses of current passing through it. In the transition zone the change of coefficients of electrical and thermal conductivity occurs from values, inherent to steel, to those of copper. At the absence of a large number of pores, cracks and other defects in it violating the density of metal, these changes occur smoothly. Therefore, in the transition zone the value of these coefficients may be taken as an average value between the coefficients of copper and steel parts. On this assumption the total electrical and thermal resistances of transition zone are determined only by its width. The transition zone of steel-copper bimetal joints, produced using different methods of welding and melting, is determined as the area of propagating the solid solutions of copper into steel and steel into copper on both sides of the interface. These solid solutions have lower values of electrical and thermal conductivity than the pure copper [7]. Thus, by measuring the thermal or electrical conductivity of the bimetal specimen in the direction perpendicular to the joining line, the width of the transition zone can be experimentally determined.

In metallic conductors a direct connection between electrical and thermal resistance exists, determined by the Wiedemann-Franz law in its modern interpretation. Thus, knowing one of these values it is always possible to determine the other one. Methodically it is much easier to measure the electrical resistance. Therefore, we conducted its evaluation using the procedure, proposed in work [7].

Mechanical properties of steel-copper specimens as compared to properties of copper

\begin{tabular}{|c|c|c|c||}
\hline Specimen number & $\begin{array}{c}\text { Yield } \\
\text { strength, MPa }\end{array}$ & $\begin{array}{c}\text { Tensile } \\
\text { strength, MPa }\end{array}$ & $\begin{array}{c}\text { Reduction in } \\
\text { area, \% }\end{array}$ \\
\hline 1 & 110.3 & 282.5 & 70 \\
\hline 2 & 113.5 & 281.0 & 73.1 \\
\hline 3 & 127.4 & 282.8 & 73.1 \\
\hline Average & 117.06 & 282.7 & 72.06 \\
\hline $\begin{array}{l}\text { Copper, wrought } \\
\text { and annealed [12] }\end{array}$ & 74 & 216 & 75 \\
\hline
\end{tabular}


From the cylinders the specimens of $4 \times 4 \times$ $\times 40 \mathrm{~mm}$ were manufactured so that the steelcopper interface was in the middle.

The measurements were carried out using the ammeter-voltmeter method in the differential variant by moving the potentiometric fork with the separation of electrodes of $2.3 \mathrm{~mm}$ at $1 \mathrm{~mm}$ pitch from the steel part to the copper one perpendicular to the fusion line. The measurement results are shown in Figure 6.

The diagram in this Figure shows that the change in electrical resistance at the steel-copper interface is concentrated on the length of about $4 \mathrm{~mm}$. However, the size of this length can not be identified with the transition zone width of our joint. In fact, it is much smaller. This is evidenced by the nature of curve of changes of electrical resistance in the area of steel-copper interface.

In fact, judging from the diagram, the initial change in resistance occurs smoothly from steel to copper during more than $2 \mathrm{~mm}$ and then decreases sharply down to the value inherent to copper. Such a form of the curve indicates that the width of transition zone is smaller than the distance between electrodes of the potentiometric fork. Therefore, the resolving capacity of the method proposed in [7], does not allow evaluating the width of thin transition zones, but only determining the average value of electrical resistance in it.

To reveal the sizes of transition zone is possible by metallographic method through investigation of microsections. Figure 7 shows microstructure of bimetal joint produced by autonomous vacuum brazing of copper on steel surface.

As a result of interaction of melt of copper M1 with steel 20 at 100 magnification the fusion line of increased etching is observed. At 1000 magnification the initial stage of penetration of copper into steel is visible. The structure of steel (ferrite + pearlite) near the fusion line is not essentially different from the rest array. Around the whole volume of the brazed copper the fine non-metallic inclusions occur, the concentration of which increases near the interface at the distance of $40-50 \mu \mathrm{m}$.

The microhardness was measured at $50 \mathrm{~g}$ load in the direction perpendicular to the fusion line. On the side of steel a sharp increase in microhardness was noted. So, in the main array of steel the microhardness amounts to about $1880 \mathrm{MPa}$. At the distance of $10-15 \mu \mathrm{m}$ from the fusion line and ahead of it the microhardness reaches to $3000 \mathrm{MPa}$. On the side of copper the abrupt changes in microhardness are not observed.

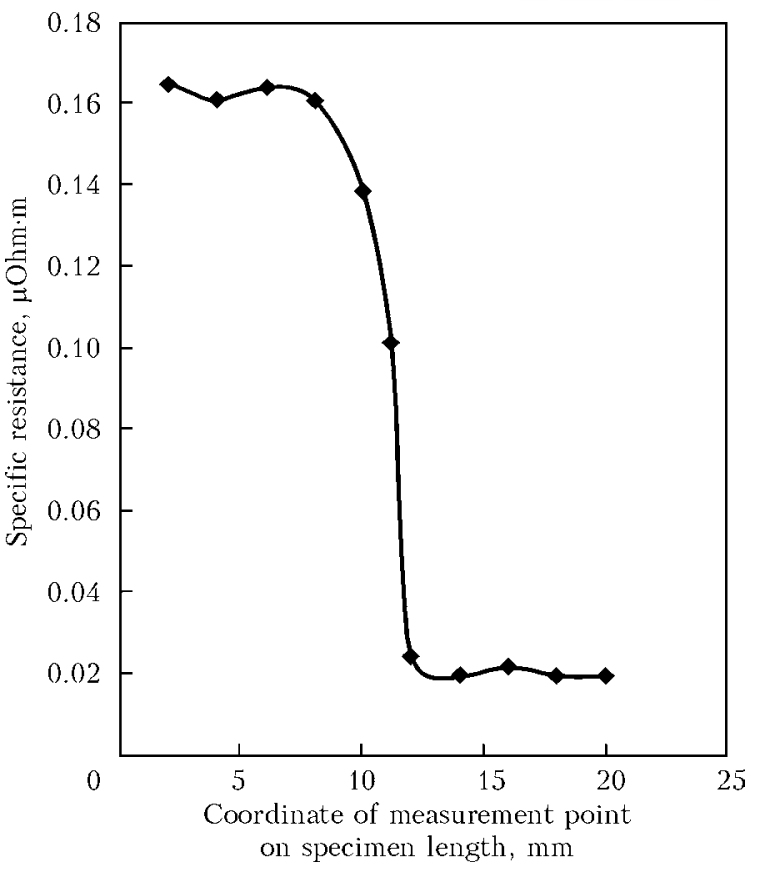

Figure 6. Diagram of changes in electrical resistance of transition zone of steel-copper bimetal produced using autonomous vacuum brazing

Across the whole cross-section of the brazed copper it amounts to 920-1080 MPa.

Thus, studying microstructure of bimetal joint on both sides of interface two anomalous regions were revealed, where the change of coefficients of electrical and thermal conductivity may occur. On the side of steel this is the area of increased
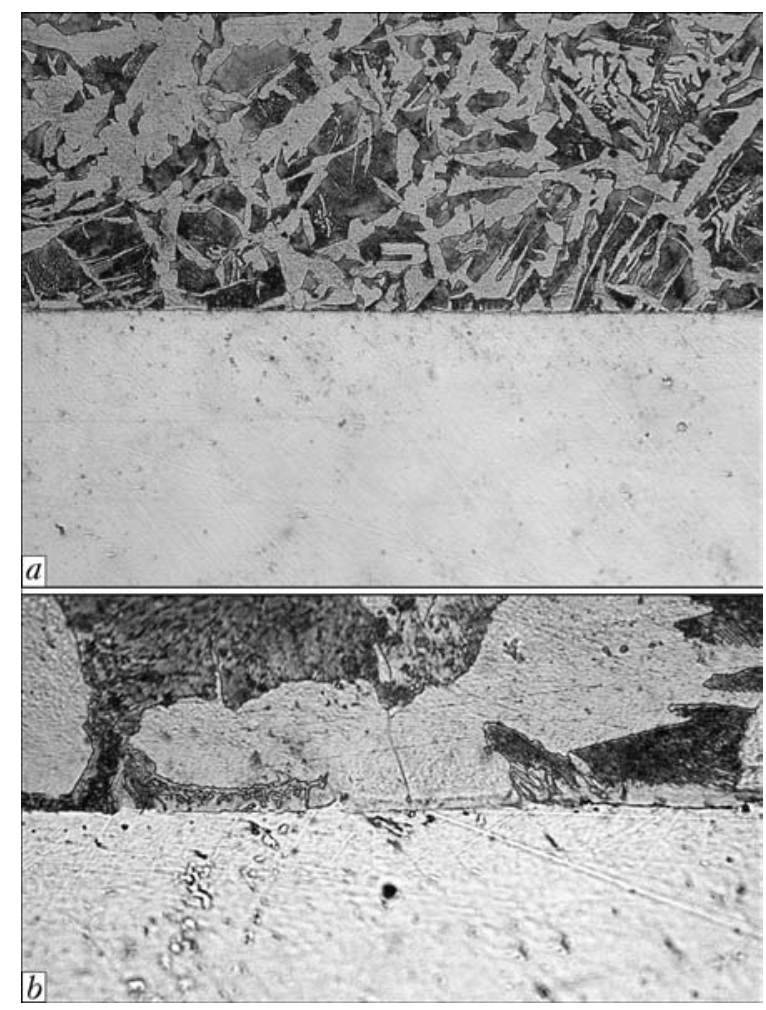

Figure 7. Microstructure of bimetal joint produced using autonomous vacuum brazing of copper on steel: $a-\times 100$; $b-\times 1000$ 
microhardness, and on the side of copper this is the area of high concentration of non-metallic inclusions.

The total length of these regions does not exceed $70 \mu \mathrm{m}$. Therefore, the size of this area may be identified with the width of transition zone from steel to copper.

This width is at least 3 times smaller than the width of each component of steel-copper bimetal. Consequently, the total additional electrical and thermal resistances of transition zone, determined as the product of mean values of resistances in it by its width, will be also 3 times lower than the resistance of each part of the bimetallic contact. Therefore, during engineering electrical and thermal calculations of bimetal steel-copper joint, produced using autonomous vacuum brazing, these additional resistances can be neglected.

\section{Conclusions}

1. The contact between steel and copper in bimetal joints, produced by autonomous vacuum brazing-on of copper, during electrical and thermal calculations can be considered perfect.

2. During tensile test the fracture of standard bimetallic specimens occurs along copper. At the same time, the strength properties of brazed copper layer exceed the reference values for deformed and annealed copper M1.

3. The ultimate tear strength of the brazed copper layer determined on the special specimens corresponds to the ultimate rupture strength of steel 20.
4. The technology of autonomous vacuum brazing can be used to produce bimetal consisting of carbon steels and copper of other grades.

1. Kuniharu, M. et al. One-sided cladding of steel sheet. Pat. 52-123824 Japan. Int. Cl. 12A 220 C 23 C $1 / 00$. Fil. 15.10.77. Publ. 8.05.79.

2. Bukov, A.A. (1979) Corrosion-resistant bimetal sheet products. Stal, 6, 446-450.

3. Nikolaev, G.A., Olshansky, I.A. (1975) Special methods of welding. Moscow: Mashinostroenie.

4. Kudinov, V.M., Koroteev, A.Ya. (1978) Explosion welding in metallurgy. Ed. by E.S. Karakozov. Moscow: Metallurgiya.

5. Nikityuk, Yu.A., Grigorenko, G.M., Zelenin, V.I. et al. (2013) Technology of restoring repair of slab mold of continuous-casting machine with friction stir surfacing. Sovr. Elektrometallurgiya, 3, 51-55.

6. Paton, B.E., Rossoshinsky, A.A. (1982) Some problems of development of brazing technology. In: Modern methods of brazing, 3-12.

7. Lakomsky, V.I., Bogachenko, A.G., Mishchenko, D.D. et al. (2013) Welded joint of copper with steel in hearth-level electrode of direct current arc furnace. Sovr. Elektrometallurgiya, 4, 7-9.

8. Paton, B.E., Medovar, L.B., Shevchenko, V.E. et al. (2003) Electroslag technologies in production of bimetal billets. Advances in Electrometallurgy, 4, 7-10.

9. Golovanenko, S.A., Meandrov, L.V. (1966) Production of bimetals. Moscow: Metallurgiya.

10. Puzrin, L.G., Bojko, G.A., Atroshenko, M.G. (1975) Autovacuum brazing. Kiev: Znanie.

11. Serebryanik, I.P., Buravlev, Yu.M., Ivanitsyn, N.P. et al. Method of production of cooled panels. USSR author's cert. 1235075. Fil. 28.06.84.

12. Keloglu, Yu.P., Zakharievich, K.M., Kartashevskaya, M.A. (1977) Metals and alloys: Refer. Book. Kishinev.

13. Ovsyannikov, V.G., Shejko, V.I., Malyshev, V.A. et al. (1976) Method of determination of tearing resistance of bimetal clad layer. Zavod Laboratoriya, 3, 339-340.

Received 30.07.2015 